The Geneva Papers on Risk and Insurance, 23 (No. 89, October 1998), 612-623

\title{
The IAIS Survey on Reinsurance Supervision An Overview of the Findings
}

\author{
by R. C. L. Bakker and H. J. M. Teeuwen*
}

\begin{abstract}
At the Third Annual Conference of the International Association of Insurance Supervisors (IAIS) held in Paris, in October 1996, one of the items of the Conference was a Panel Session on reinsurance and supervision. Chairing this session, the Verzekeringskamer (the Dutch Insurance Supervisory Authority) focused on how reinsurance supervision is practised in a number of IAIS countries. Moreover, these countries were invited to give their opinion about the future supervision on reinsurance. At the end of the Panel Session, the Verzekeringskamer invited all members of the IAIS to fill in a questionnaire on this subject in due course.

At the Fourth Annual Conference, in Sydney Australia, in September 1997, the results of a research project were made public. This article is a slightly adapted version of the paper that was presented in Sydney.

The main results indicate that the IAIS members expect a somewhat stricter supervision of reinsurers than at present. The existing differences in supervisory approach between the countries will narrow, but will not disappear altogether.
\end{abstract}

\section{Introduction}

One of the foremost aims of the IAIS is the exchange of information and experiences between the supervisory authorities of the member countries. Knowledge of the supervisory systems - and practices - of the fellow members clearly is a prerequisite to

\footnotetext{
* The Netherlands Supervisory Authority (Verzekeringskamer), The Netherlands.
} 
establishing the efficient and effective co-operation in supervision that the modern insurance markets demand. It is with this in mind that the Insurance Supervisory Board of the Netherlands proposed to carry out a survey on reinsurance supervision in the IAIS member states.

For an insurer the main role of reinsurance is stabilisation of the results, thus maintaining the continuity of the insurance company. This, finally, is in the best interests of the policy holders. Reinsurance, of course, can only fulfill this role if the insurance company can at all times count on the financial solidity of the reinsurers. This is where supervision on reinsurers comes into play.

The reinsurance market - which is strongly international in character - can only work properly if a number of preconditions are met. It should not unduly be constrained by legislation in individual countries. And where legislation is deemed necessary, it should not create an inequality which frustrates fair and effective competition.

In the last decade or so some major changes have taken place in the reinsurance market. Natural catastrophes and changing views on liability have substantially impaired the financial position of many reinsurers. This, in turn, has also effected the direct insurers: capacity shortages, limitation of cover or even uninsurability, and an increase in reinsurance tariffs. In some instances this has led to a less appropriate reinsurance policy by the direct insurers.

These developments have encouraged a concentration in the reinsurance market. At the same time there has been a rapidly growing interest in financial reinsurance, with a more recent distinction between finite reinsurance and the so-called alternative risk market. It is expected that such products can be tailored more specifically to the needs of the insurers, principally a more fundamental improvement in the diversification of risk.

Naturally, these issues have not gone unnoticed by the supervisory authorities, and have spurned a (re-)consideration of the most appropriate form of supervision - if any on reinsurers. The IAIS is one of the main platforms for this discussion. It is therefore that at the 3rd IAIS Conference in Paris, in October 1996, the Insurance Supervisory Board of the Netherlands proposed to hold a survey amongst the IAIS members on their views and practices of reinsurance supervision.

\section{Survey aim and procedure}

\subsection{Aim}

Current reinsurance supervision differs between the various IAIS countries, but to date a publicly available complete overview did not exist. Also, as mentioned in the introduction, the strong cross-border nature of the reinsurance markets necessitates insight in, and an exchange of thoughts on, the most desirable form of co-operation in reinsurance supervision.

The aim of the survey was thus twofold:

1. To provide an overview of the current regulation and practices of reinsurance supervision. 
2. To provide an overview of the expectations of each of the IAIS members on future regulation:

- in their own country;

- worldwide.

The factual information thus collected can then serve as a basis for subsequent research and discussion.

\subsection{Data}

In December 1996 a survey questionnaire ${ }^{1}$ was sent to each of the IAIS members. To indicate the current and expected type of supervision in their own country five main types, or "levels", of reinsurance supervision were distinguished:

0 . no supervision at all;

1. supervision on reinsurance is restricted to ceded reinsurance of direct insurers only;

2. the supervisor is authorised to request for non-public information of a domestic reinsurer;

3. every reinsurer doing business with a domestic insurer is licensed;

4. uniform licensing should be extended with additional requirements for the insurer or reinsurer.

To indicate the present situation only the alternatives $0 .-3$. could be selected; level 4 . would only apply to the future expectations.

Considering the big differences in the practices of actual supervision the survey questionnaire also focused on further distincting sub-levels of supervision. This would allow the anticipated future main level to be correlated to the specific circumstances in a country.

Table 1 shows the sub-levels contained in the survey questionnaire. The digital part of the sub-level code in this table relates in a certain sense to the code of the main levels. This relation is suggested in the survey questionnaire at forehand, but does not necessarily have to be confirmed afterwards.

To indicate the expected future type of reinsurance supervision on a worldwide basis, a choice between two alternatives was offered: sustained disparities between countries in the type of supervision, or (a trend towards) harmonisation in supervisory approach.

\subsection{Set-up of the analysis}

The classification by the five main levels will be sufficiently clear to get to a global insight into the actual position and future shifts of main types of supervision. In a graphical way the combination of the present and future main level of each country can be shown as a $(x, y)$-point in a diagram, the $x$ and $y$ representing the present and future types respectively. (At the same time the integer point $x$ on the $x$-axis may also be considered as the position of a country with present main level $x$ within the spectrum of main levels of supervision.) In other words, the future situation may be considered as a function of the

${ }^{1}$ We much appreciate the valuable comments on an earlier draft of the survey questionnaire by a few fellow IAIS members. 
Table 1: sub-levels of supervision in the survey questionnaire

\begin{tabular}{|c|c|}
\hline $1 \mathrm{a}$ & reinsurers do not have to submit accounts \\
\hline $1 b$ & only domestic reinsurers have to submit annual accounts to the supervisor \\
\hline $1 \mathrm{c}$ & $\begin{array}{l}\text { all reinsurers involved with domestic insurers have to submit annual accounts } \\
\text { to the supervisor }\end{array}$ \\
\hline $1 d$ & $\begin{array}{l}\text { the direct insurers' gross technical provisions may be offset by technical } \\
\text { provisions for ceded reinsurances as far as pledged as collateral security by } \\
\text { the reinsurer }\end{array}$ \\
\hline $1 \mathrm{e}$ & regarding foreign reinsurers rating agencies' information is used \\
\hline $2 \mathrm{a}$ & the supervisor may practice on-site inspections at the reinsurers' premises \\
\hline $2 b$ & inquiry authorization is applicable to foreign reinsurers as well \\
\hline $2 \mathrm{c}$ & the direct insurer is restricted in choosing its reinsurer \\
\hline $2 \mathrm{~d}$ & the direct insurer is restricted in the amount of reinsurance ceded \\
\hline $2 \mathrm{e}$ & $\begin{array}{l}\text { only domestic reinsurers should have an approval in advance (no solvency } \\
\text { requirements) }\end{array}$ \\
\hline $2 \mathrm{f}$ & all reinsurers should have an approval in advance (no solvency requirements) \\
\hline $2 \mathrm{~g}$ & $\begin{array}{l}\text { domestic reinsurers follow the same financial rules for disclosure as direct } \\
\text { insurers }\end{array}$ \\
\hline $3 a$ & the licensing system is determined country by country \\
\hline $3 b$ & only one worldwide licensing system restricted to the most relevant branches \\
\hline $3 \mathrm{c}$ & only one non-restricted worldwide licensing system is applicable \\
\hline $3 \mathrm{~d}$ & the principles of supervising reinsurers are the same as for direct insurers \\
\hline $3 e$ & $\begin{array}{l}\text { supervision of reinsurers is applied only as an alternative to supervision of } \\
\text { reinsurance ceded of direct insurers }\end{array}$ \\
\hline $3 \mathrm{f}$ & $\begin{array}{l}\text { supervision of reinsurers is applied in addition to supervision of reinsurance } \\
\text { ceded of direct insurers }\end{array}$ \\
\hline $3 g$ & the supervisor assesses the reinsurers' solvency \\
\hline
\end{tabular}

present type. In this context the diagonal in the diagram represents the case that the future type of supervision is expected to be the same as the present, implying $y=x$, as shown as the starting position in Graph 1a.

Any anticipated real change in a country's main level is reflected by a point (x,y') away from the diagonal $\left(y^{\prime} \neq x\right)$. The anticipated future main levels of all countries can thus be shown as an integer-valued scatter diagram. By simply applying an OLS estimate, a line can be drawn reflecting the relation between the anticipated future and present main level of supervision. 


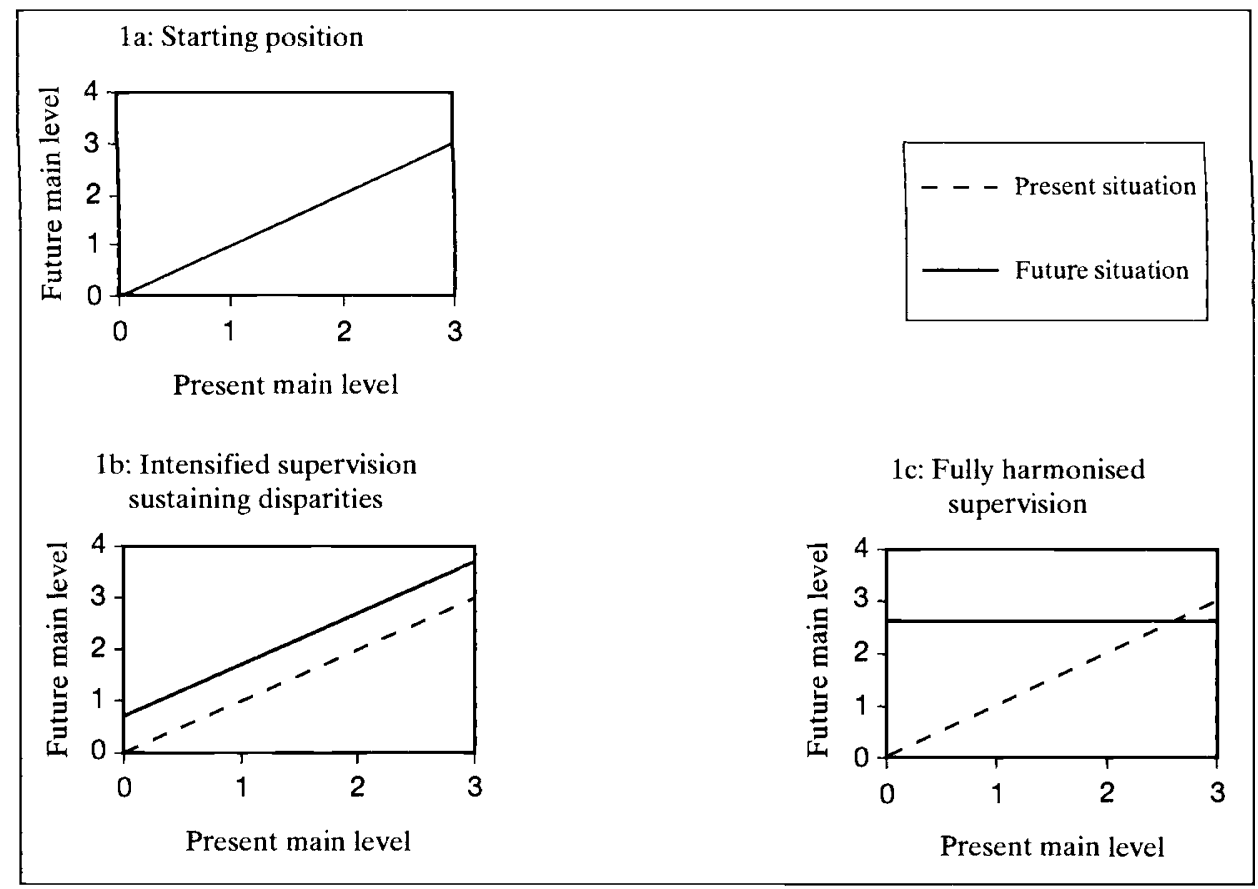

Graphs $1 \mathrm{~b}$ and $1 \mathrm{c}$ illustrate two possible situations of anticipated future main level of supervision. In the first case all supervisors would intend to intensify supervision. A straight line parallel to the diagonal results reflecting the weight of each actual position, without any harmonisation. Graph 1c shows the other case where all supervisors would apply for the same harmonised level, resulting in a horizontal line.

The aim of this survey is to establish a graphical insight into the anticipated global shifts allowing the anticipated main level of supervision to be explained analytically from the disposed line (in respect of the diagonal).

Finally the survey could produce a list of factors that will be really of importance to possible changes in supervision on reinsurance to come.

\section{Survey results}

\subsection{Present and anticipated situation per country: main level of supervision}

It is illustrative to start with the results in a graphical way. Each country ${ }^{2}$ is plotted in the diagram by its combination of present main level (horizontal axis) and anticipated

2 Of the 87 questionnaires that were distributed, 63 were received back in due time. Of these, 58 forms were completed sufficiently to be used for further analysis. 
future main level (vertical axis). The line reflecting the relation between the current and the expected level of supervision is found by OLS estimation and has to be compared to the diagonal, the case where there would be no changes at all.

Graph 2: shift of main level of reinsurance supervision by IAIS member country

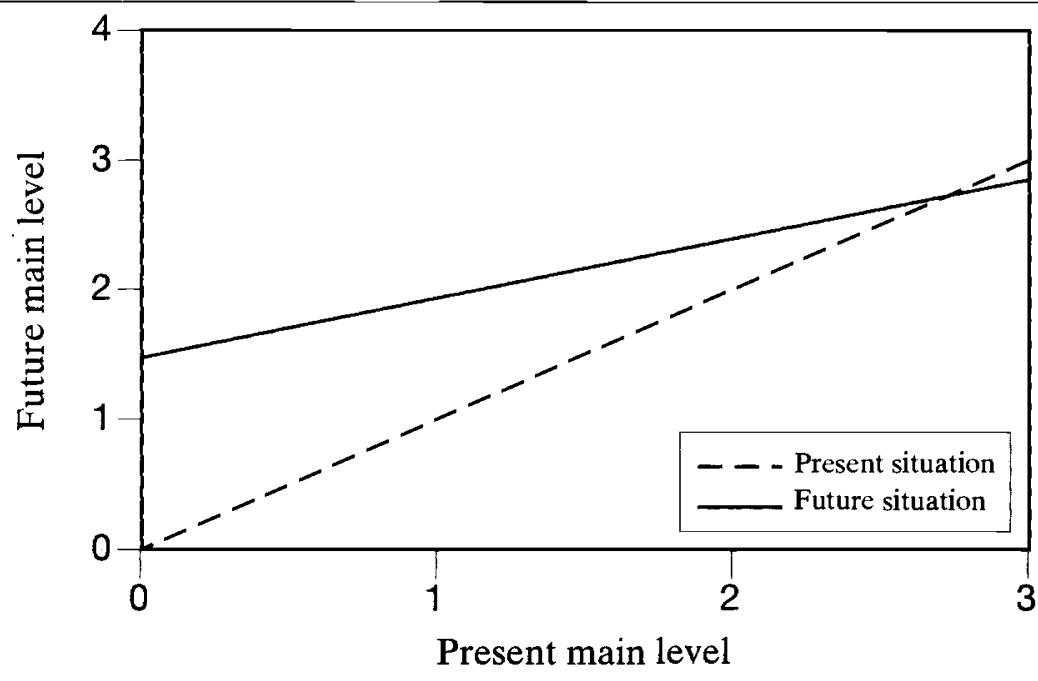

Graph 2 illustrates, first, that on average supervision is expected to be intensified the "future" line on average lies above the diagonal - and, second, that a certain convergence is expected to take place, whereby those countries with currently no, or limited supervision, will move towards the countries which already employ a somewhat stricter form of supervision - the slope of the "future" line is clearly less steep than the diagonal line.

Table 2 summarises the main levels of reinsurance supervision per country, both the present and anticipated future level.

Table 2: number of countries distinguished according to present and anticipated main level of supervision in their own country

\begin{tabular}{|c|c|c|c|c|c|c|}
\hline \multirow{2}{*}{$\begin{array}{l}\text { Number of } \\
\text { countries }\end{array}$} & \multicolumn{5}{|c|}{ Main level of supervision } & \multirow[b]{2}{*}{ Total } \\
\hline & 0 & 1 & 2 & 3 & 4 & \\
\hline Present situation & 3 & 9 & 25 & 21 & - & 58 \\
\hline Future situation & 0 & 5 & 29 & 17 & 7 & 58 \\
\hline
\end{tabular}

A clear majority of countries already exercise some form of supervision on reinsurers. It is generally expected that the supervision will be somewhat intensified. The "average" main level will move from the current 2.1 to 2.5 . 
At a closer look at the cell values in the diagram some interesting details may be noticed. Although the shifted line indicates a change, a great number of countries is still found on the diagonal. In the largest cell of the diagram $(2,2), 22$ countries expect no change (compared with 25 and 29 countries with present and anticipated future main level respectively). At main level 3 , there are 15 countries in cell $(3,3)$, compared with the 21 and 17 with present and anticipated future main level 3. At main level 1 , there are 4 countries in cell $(1,1)$ (compared with 9 and 5 as above).

Further, it is worth mentioning that 15 (out of 58) countries expect a higher future main level; 9 of them by increase of 1 level, 5 by increase of 2 levels and 1 by increase of even 4 levels. On the contrary, only 2 countries anticipate a lower main level (1 country decreasing by 1 level, the other by 2 levels).

For a better insight into the shift in supervision a more detailed analysis of the underlying responses is required. Table 3 gives an overview of the present and anticipated future main level of supervision for all countries and specifically countries that foresee a change on a local level. In addition, a breakdown is given between OECD-like countries and non-OECD countries ${ }^{3}$.

Table 3: present and anticipated future local main levels of supervision

\begin{tabular}{|c|c|c|c|c|c|c|c|c|c|}
\hline & & & & ber & cou & & & & \\
\hline Category & countries & & in 16 & of & ervi & & & & evel \\
\hline & & 0 & 1 & 2 & 3 & 4 & Total & & \\
\hline All countries & & & & & & & & & \\
\hline All & Present & 3 & 9 & 25 & 21 & - & 58 & 2.1 & \\
\hline & Future & 0 & 5 & 29 & 17 & 7 & 58 & & 2.5 \\
\hline OECD-like & Present & 1 & 5 & 23 & 12 & - & 41 & 2.1 & \\
\hline & Future & 0 & 2 & 24 & 12 & 3 & 41 & & 2.4 \\
\hline Non- & Present & 2 & 4 & 2 & 9 & - & 17 & 2.1 & \\
\hline OECD-like & Future & 0 & 3 & 5 & 5 & 4 & 17 & & 2.6 \\
\hline Countries ant & pating cha & & & & & & & & \\
\hline All & Present & 3 & 5 & 3 & 6 & - & 17 & 1.7 & \\
\hline & Future & 0 & 1 & 7 & 2 & 7 & 17 & & 2.9 \\
\hline OECD-like & Present & 1 & 3 & 3 & 1 & - & 8 & 1.5 & \\
\hline & Future & 0 & 0 & 4 & 1 & 3 & 8 & & 2.9 \\
\hline Non- & Present & 2 & 2 & 0 & 5 & - & 9 & 1.9 & \\
\hline OECD-like & Future & 0 & 1 & 3 & 1 & 4 & 9 & & 2.9 \\
\hline
\end{tabular}

${ }^{3}$ OECD-like countries consist of both OECD-members and those countries which are not OECD-members but which have strong historic and legal ties with an OECD country. 
For countries expecting no changes (not shown in table 3 ) the average main level amounts to 2.3, for both 33 OECD-like and 8 non-OECD-like countries.

The countries anticipating change in their own country tend to have less supervision on reinsurers, or none at all, than those which do not expect a change in the level of supervision. Of the countries expecting a change, the OECD-like countries in particular have at present a low "average" level of supervision; the non-OECD-like countries here apparently have relatively strongly diverging supervision: either level 0 and 1 , or level 3.

Interestingly, those countries which foresee a change, expect a quite significant intensification of supervision (from on average 1.7 to 2.9 ), and thus provide an average which is well above that of the countries which do not anticipate a change (2.3). All countries expect that in future there will be at least some form of supervision. When considering the averages, the OECD-like and non-OECD-like countries seem remarkably similar. However, as may be read in table 3, there appears to be somewhat more divergence in the responses of the non-OECD-like countries.

\subsection{Present and anticipated situation per country: sub-level of supervision}

The survey was primarily aimed at gaining an insight into the main levels of supervision, both present and anticipated. However, it also seemed useful to offer the IAIS-members the opportunity to specify the current and expected supervisory approach in some detail, by including a number of sub-levels in the questionnaire.

Of the sub-levels specified, six were selected by at least one-third of the respondents, either for the present or for the future situation. These were:

1b: only domestic reinsurers have to submit annual accounts to the supervisor;

1e: regarding foreign insurers rating agencies' information is used;

2a: the supervisor may practise on-site inspections at the reinsurers' premises;

$2 \mathrm{~g}$ : domestic reinsurers follow the same financial rules for disclosure as direct insurers;

$3 \mathrm{~d}$ : the principles of supervising reinsurers are the same as for direct insurers;

$3 \mathrm{~g}$ : the supervisor assesses the 'reinsurers' solvency.

Table 4 summarises the number of countries selecting these six sub-levels, for both the current and future situation.

Table 4: the sub-levels of supervision selected most often

\begin{tabular}{|l|c|c|c|c|c|c|}
\hline \multirow{2}{*}{ Number of countries } & \multicolumn{6}{|c|}{ Sub-level of supervision } \\
\cline { 2 - 8 } & $1 \mathrm{~b}$ & $1 \mathrm{e}$ & $2 \mathrm{a}$ & $2 \mathrm{~g}$ & $\mathbf{3 d}$ & $\mathbf{3 g}$ \\
\hline Present situation & 22 & 18 & 35 & 34 & $\mathbf{1 9}$ & $\mathbf{2 0}$ \\
\hline Anticipated future situation & 22 & 22 & 36 & 36 & $\mathbf{2 4}$ & $\mathbf{2 2}$ \\
\hline of which both present and future & 18 & 14 & 31 & 29 & $\mathbf{1 7}$ & $\mathbf{1 7}$ \\
\hline
\end{tabular}


Overall, there appeared to be quite a strong correlation in the answers between the present and expected future situation, as may also be read from this table.

In the questionnaire, each of the main levels had a number of sub-levels attached. However, for some countries a different combination of main and sub-level best described their supervisory approach. Table 5 provides an overview of the relation between the six selected sub-levels and each of the main levels. The percentages in the table show how often a certain sub-level is indicated by those countries for which the associated main level applies.

Table 5: relation between sub-levels and main levels of supervision

\begin{tabular}{|c|c|c|c|c|c|c|c|c|}
\hline \multirow{3}{*}{\multicolumn{2}{|c|}{$\begin{array}{c}\text { Main level } \\
\text { of supervision } \\
\text { by situation }\end{array}$}} & \multirow{3}{*}{$\begin{array}{c}\text { Number of } \\
\text { countries } \\
(=N)\end{array}$} & \multicolumn{6}{|c|}{ Sub-level of supervision } \\
\hline & & & $1 b$ & $1 \mathrm{e}$ & $2 \mathrm{a}$ & $2 \mathrm{~g}$ & $3 \mathrm{~d}$ & $3 g$ \\
\hline & & & \multicolumn{6}{|c|}{ as a percentage of $\mathrm{N}$} \\
\hline \multirow[t]{2}{*}{0} & present & 3 & 0 & 0 & 0 & 0 & 0 & 0 \\
\hline & future & 0 & 0 & 0 & 0 & 0 & 0 & 0 \\
\hline \multirow[t]{2}{*}{1} & present & 9 & 55 & 55 & 22 & 55 & 0 & 33 \\
\hline & future & 5 & 60 & 60 & 20 & 60 & 20 & 40 \\
\hline \multirow[t]{2}{*}{2} & present & 25 & 48 & 36 & 88 & 80 & 36 & 24 \\
\hline & future & 29 & 45 & 48 & 79 & 76 & 31 & 21 \\
\hline \multirow[t]{2}{*}{3} & present & 21 & 23 & 19 & 53 & 43 & 48 & 52 \\
\hline & future & 17 & 29 & 12 & 41 & 35 & 59 & 53 \\
\hline \multirow[t]{2}{*}{4} & present & - & - & - & - & - & - & - \\
\hline & future & 7 & 14 & 43 & 71 & 71 & 57 & 71 \\
\hline \multirow[t]{2}{*}{ Total } & present & 58 & 38 & 31 & 60 & 59 & 33 & 34 \\
\hline & future & 58 & 38 & 38 & 62 & 62 & 41 & 38 \\
\hline
\end{tabular}

This table illustrates that fairly high percentages are also found for combinations of main level and sub-level which differ from the assignment of sub-levels in the questionnaire. This indicates that there is a reasonably broad consensus on the importance of these specific supervisory elements. Also, the percentages found under the heading "future" suggest that these sub-levels will play a pivotal role in a trend towards harmonisation.

We also analysed to what extent a combination of any two sub-levels occurred in the responses, for both the present and the anticipated future situation. The sub-levels ticked most often are $2 \mathrm{a}$ and $2 \mathrm{~g}$, underlining the importance of on site inspections at the reinsurers' premises and the similarity of disclosures rules for both direct insurer and reinsurer. Nearly two-third of all countries opt for these sub-levels separately, whereas half of all countries opt for both sub-levels at the same time. So, the combination $(2 \mathrm{a}, 2 \mathrm{~g})$ showed most prominent. Less but still noteworthy correlated coincidences of sub-levels 
were found in the combinations $(1 \mathrm{~b}, 2 \mathrm{~g})$ and $(3 \mathrm{~d}, 3 \mathrm{~g})$. Correlated triples of sub-levels showed up to be combinations of the above mentioned couple $(2 \mathrm{a}, 2 \mathrm{~g})$ with either $1 \mathrm{~b}$ or $3 \mathrm{~d}$.

\subsection{Anticipated reinsurance supervision worldwide}

A further main question in the survey concerned the type of supervision expected on a worldwide basis. Each IAIS member was asked to choose between two main alternatives, sustained disparities between countries or a trend towards harmonisation.

For this analysis the answers of 53 countries could be used. Of these, 23 countries expect that differences in the style of supervision on reinsurers will persist. A small majority, 30 countries, foresee a trend towards harmonisation of supervisory practices.

Sustained disparities, however, might well be at a "higher" or "lower" level of supervision. Equally, harmonisation could be at any of the levels distinguished, or a position somewhere in between.

In full analogy to graph 2 , the anticipated main level by country is visualised in graph 3 , distinguished by the two opposite options for the anticipated level of supervision worldwide.

Graph 3: shift of main level of reinsurance supervision by IAIS member country, conditioned by its option of supervision worldwide

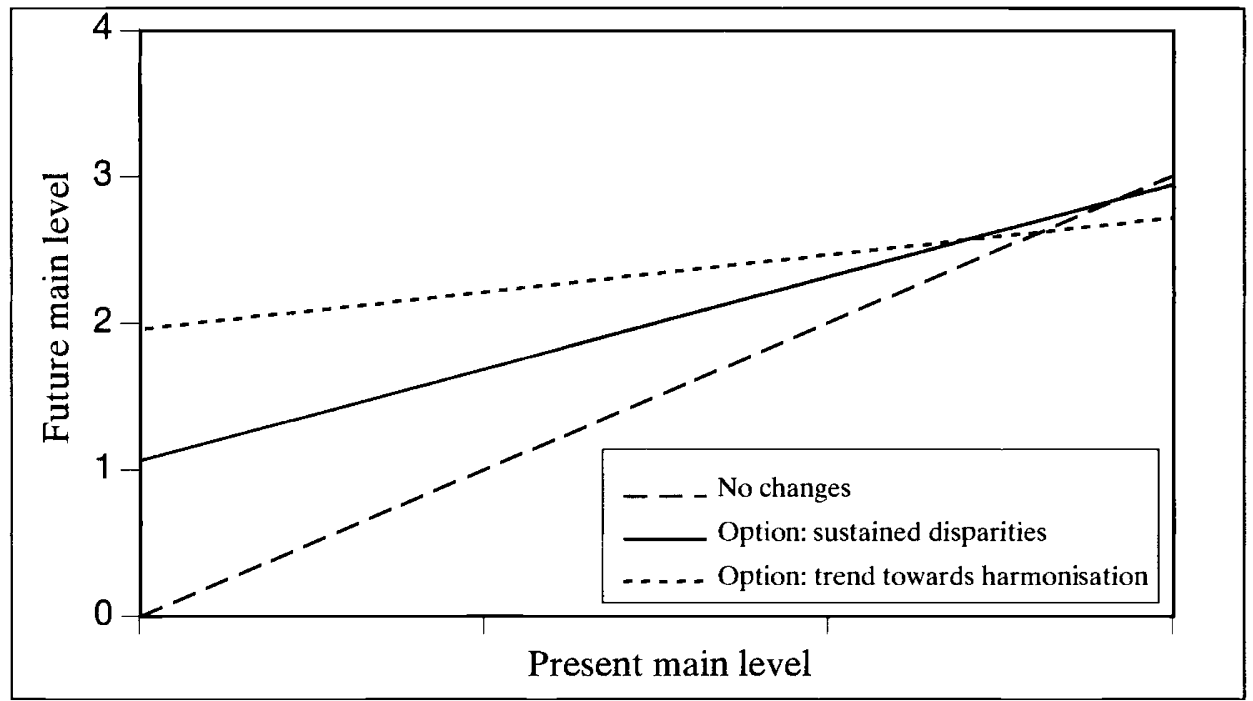

For countries that believe in sustained disparities in supervision worldwide the difference between countries are expected to fade somewhat. Otherwise, countries that anticipate worldwide harmonisation do not seem to agree on a very specific level of harmonisation yet. 
Table 6 summarises the answers, also distinguishing between countries according to both the present main level of supervision, and the level they foresee in their own country.

Table 6: anticipated reinsurance supervision worldwide, relative to main level per country

\begin{tabular}{|c|c|c|c|c|c|c|c|c|}
\hline \multirow{3}{*}{$\begin{array}{l}\text { Options of supervision } \\
\text { worldwide }\end{array}$} & & \multicolumn{6}{|c|}{ Number of countries } & \multirow{3}{*}{$\begin{array}{c}\text { Average } \\
\text { main } \\
\text { level }\end{array}$} \\
\hline & & \multicolumn{5}{|c|}{ By present and future main level } & \multirow[b]{2}{*}{ Total } & \\
\hline & & 0 & 1 & 2 & 3 & 4 & & \\
\hline \multirow[b]{2}{*}{ Sustained disparities } & present & 1 & 5 & 10 & 7 & - & 23 & 2.0 \\
\hline & future & 0 & 2 & 14 & 5 & 2 & 23 & 2.3 \\
\hline \multirow{2}{*}{ Trend towards harmonisation } & present & 2 & 4 & 12 & 10 & - & 30 & 1.9 \\
\hline & future & 0 & 3 & 14 & 8 & 5 & 30 & 2.5 \\
\hline
\end{tabular}

Those countries which expect a continuation of disparities still on average expect an increase in the future level of supervision, from 2.0 to 2.3 . The countries which foresee a trend towards harmonisation also expect a "higher" level of reinsurance supervision, from on average 1.9 to 2.5 .

Finally, table 7 reflects the anticipated type of supervision of the IAIS member countries worldwide by further distinguishing the category which the country belongs to. Also here, it can be noted that relatively more non-OECD-like countries than OECD-like countries expect a trend towards harmonisation.

Table 7: anticipated reinsurance supervision worldwide by category of countries

\begin{tabular}{|l|c|c|c|}
\hline \multirow{2}{*}{ Options of supervision worldwide } & \multicolumn{3}{|c|}{ Number of countries } \\
\cline { 2 - 4 } & Total & OECD-like & Non-OECD-like \\
\hline Sustained disparities & 23 & 18 & 5 \\
\hline Trend towards harmonisation & 30 & 19 & 11 \\
\hline
\end{tabular}

\section{Conclusion}

The aim of this survey was to give some indicative and only preliminary insight into the current supervisory practices of the IAIS members, and the direction of any anticipated changes therein. We are pleased to be able to say that the very limited questionnaire has generated a lot of information and interest. This encouragement would suggest a continuing role for the IAIS to facilitate and stimulate a further structuring and exchange of information between the IAIS members.

The results indicate that the IAIS members expect, firstly, that overall the supervision of reinsurers will in future be somewhat stricter than at present. Secondly, that the existing differences in supervisory approach between the countries will narrow, but will not disappear altogether. Interestingly, those countries which expect a change in supervision presently employ on average a level of supervision which is lower than that of the countries which anticipate no changes, whilst in future their average would be higher. 
The total expected intensification of supervision can be seen as a combination of two elements. Countries which expect a continuation of disparities on a worldwide basis on average expect an increase in the future level of supervision in their home country. Also, the countries which foresee a trend towards harmonisation worldwide expect this to be at a higher level of reinsurance supervision in their own country; the change here is stronger than expected by the first group of countries.

On a sub-level of supervisory items the most significant items regard to the on site inspections and to the disclosure issues, of which a coincidental occurrence of both items is remarkable. Especially these items may serve as a catalyst for further research and discussion within - and of course also outside - the IAIS. 